Eur. J. Clin. Chem. Clin. Biochem.

Vol. 29, 1991, pp. 269-275

(C) 1991 Walter de Gruyter \& Co.

Berlin - New York

\title{
Establishment of Reference Methods for Lipids, Lipoproteins and Apolipoproteins ${ }^{1}$ )
}

\author{
By G. R. Cooper, G. L. Myers and L. O. Henderson \\ Centers for Disease Control, Public Health Service, U.S. Department of Health and Human Services, Atlanta, \\ Georgia, USA
}

(Received January 22, 1991)

Summary: Reference methods for lipids, lipoproteins, and apolipoproteins have been developed for use as part of an accuracy base for institutional, national, or international reference systems. A widely accepted reference method exists only for total cholesterol. Well described interim or institutional in-house reference methods have been established for the other lipids, lipoproteins, and apolipoproteins. The major criteria for a reference method are

1) scientific basis,

2) sound principles,

3) available calibration and control materials,

4) traceability to a definitive method or a point of reference, and

5) applicability to reference materials that provide traceability to clinical methods and transferability to other reference laboratories.

The total cholesterol reference method of the U.S. National Reference System demonstrates how a reference method can be developed and applied. Reference methods now available can lead to an accepted international accuracy base for the clinically useful lipid, lipoprotein, and apolipoprotein measurements.

\section{Introduction}

Reference methods are essential components of the accuracy base of any established reference system for lipids, lipoproteins, and apolipoproteins. A stable accuracy base depends upon availability. of a stable reference method and reference materials. Together,

1) Contribution of the International Federation of Clinical Chemistry (IFCC) Working Group on Apolipoprotein Reference Methods established at the Centers for Disease Control and the IFCC Committee on Apolipoproteins (S. M. Marçovina, chaịrman, J. J. Albers, J. C. Fruchart, M. Rosseneu, J. Shepherd) of the IFCC Scientific Division (H. Greiling, chairman, $M$. M. Müller, vice chairman).

Based on a lecture given at the Symposium "Reference Methods in Clinical Chemistry - Objectives, Trends, Problems" of the Congress Biochemische Analytik 90, München, May 8,1990 a reference method and reference material play a significant role in transferring the accuracy base of a definitive method to the clinical laboratory. Reference methods are considered acceptable when they possess

1) known minimum bias versus a definitive method,

2) known sound scientific basis,

3) available calibration and quality control reference material, and

4) traceability to clinical methods and their secondary serum reference material.

The more widely available reference methods designed for widespread use and application must be validated by the less available definitive method (1). A purified 
primary standard is required to calibrate the definitive method and reference method while commutable secondary serum reference materials are used to calibrate clinical methods of lipids, lipoproteins, and apolipoproteins. A higher productivity or throughput than the definitive method provides is desirable to satisfy multiple demands placed upon a reference method.

Reference methods are developed to assure accuracy of clinically useful laboratory procedures. Procedures for lipid, lipoprotein, and apolipoprotein considered highly useful to the clinicians in the detection, prevention, and control of coronary heart disease and secondary hyperlipidaemia diseases are quantitative measurements of total cholesterol, triacylglycerol, high-density lipoprotein (HDL) ${ }^{2}$ ) and low-density lipoprotein (LDL), cholesterol, and apolipoproteins A1 and $\mathrm{B}$. These therefore will be discussed here.

Reference methods have been established at the Centers for Disease Control (CDC) for total cholesterol, triacylglycerol, $\mathrm{HDL}$ cholesterol, and apolipoprotein A-1 and B (2). The total cholesterol method has been accepted as the total cholesterol reference method of the US National Reference System for Cholesterol established by the National Committee for Clinical Laboratory Standards (NCCLS) (3). The US National Reference System for Cholesterol comprises the isotope dilution and mass spectrometric definitive method of the National Institute of Standards and Technology (NIST) (4), CDC modified Abell - LevyBrodie - Kendall (5) total cholesterol reference method $(6,7)$, NIST-certified pure cholesterol standard, and NIST- and CDC-certified serum based secondary reference material (8). The NCCLS has accepted the CDC in-house reference methods for triacylglycerol and HDL cholesterol as NCCLS interim reference methodological principles for the U.S. National Reference System. CDC and the Committee on Apolipoproteins of the International Federation of Clinical Chemistry (IFCC) are collaborating in studies designed to select candidate reference methods for apolipoproteins A-1 and B.

The total cholesterol reference method will be discussed in greater detail than those of the other lipids, in order to illustrate the characteristics, requisites, and applications of a reference method and its role in standardization.

2) Non-standard abbreviations:

CDC Centers for Disease Control

NIST National Institute for Standards and Technology

SRM Standard Reference Material

RIA radioimmunoassay

VLDL very low-density lipoprotein

IDL intermediate-density lipoprotein

LDL low-density lipoprotein

HDL high-density lipoprotein

\section{Essential Characteristics of a Reference Method}

The major criteria for a reference method are

1) scientific basis,

2) sound principles,

3) available calibration and control materials,

4) traceability to a definitive method or a point of reference,

5) applicability to reference materials that provide traceability to clinical methods, and

6) transferability to other reference laboratories $(9-12)$.

The scientific basis is judged by accuracy, precison, linearity of dose-response, specificity, stability of reagents, interferences, recovery, and ruggedness. Sound principles demand that each analytical step must be defined and controlled, possess appropriate sensitivity, permit accurate sampling and dilutions, use stable equipment, calculate results by accepted procedures, and be subject to acceptable analysis of variance. Each reference method should use a defined purified primary standard or defined serum biological reference preparation for use in calibration or monitoring. The serum reference materials should have minimum matrix effects, be stable over time, and permit valid assignment of mass values. Directions for the reference method should be written so clearly that the reference method can be transferred to other laboratories without any instructions other than the directions. These essential characteristics form the criteria that a method must meet to be considered as a candidate reference method for the measurement of lipids, lipoproteins, and apolipoproteins in serum or other body fluids.

\section{Total Cholesterol Reference Method}

In 1975, the Cholesterol Reference Method Study Group of the American Association for Clinical Chemistry (AACC) invited the CDC to develop a candidate total cholesterol reference method. During the five-year development period (1977-1982), five potential candidate methods were selected, optimized, and compared. The top two methods (Abc/l-LevyBrodie-Kendall (5) and an enzymic procedure) were selected on the basis of these studies, and were then compared with the NIST=developed isotope dilutionmass spectrometric definitive method (4). On the basis of these comparisons, the American Association for Clinical Chemistry Cholesterol Reference Method Study Group selected the Abell $\div$ Levy-Brodie-Ken- 
dall method as the recommended total cholesterol reference method (5). The Abell-Levy-BrodieKendall method was next subjected to extensive validation studies (6) and a transferability study with 14 collaborating lipid laboratories throughout the United States (7). The transferability study demonstrated that the recommended reference method permits laboratories to attain a coefficient of variation (CV) of less than $1.5 \%$ within the laboratory and CV of less than $3.0 \%$ among the 14 laboratories. The mean percent bias value of the 14 laboratories compared with that of the CDC was less than $1 \%$ for six of the 14 laboratories, less than $1.5 \%$ for 12 , and less than $3 \%$ for all 14 laboratories (7). Interestingly, a preliminary readiness testing and competence evaluation predicted the quality of analytical performance exhibited during the transferability testing.

The total cholesterol reference method procedure includes the following steps: a $0.5-\mathrm{ml}$ sample in $20 \mathrm{~g} / 1$ alcoholic $\mathrm{KOH}$ undergoes hydrolysis at $50^{\circ} \mathrm{C}$ for $1 \mathrm{~h}$; the hydrolysate is extracted with hexane by vigorous shaking at $25^{\circ} \mathrm{C}$ for $15 \mathrm{~min}$; an aliquot of hexane is evaporated in a vacuum oven at $55^{\circ} \mathrm{C}$; colour is developed by reaction with a reagent formed from 20 parts acetic anhydride, 1 part $\mathrm{H}_{2} \mathrm{SO}_{4}$, and 10 parts glacial acetic acid at $25^{\circ} \mathrm{C}$ for exactly $30 \mathrm{~min}$; and an absorbance reading is taken at $620 \mathrm{~nm}$ in a flowthrough cuvette.

Calibration is performed with NIST pure cholesterol standard reference material $911 \mathrm{~b}(6)$. Since 1978, analytical performance of the total cholesterol reference method at CDC has exhibited a $\overline{C V}$ of less than $1 \%$ and a bias rarely above $1 \%$ on frozen serum pools (tab. 1).

Tab. 1. Performance of total cholesterol reference method, CDC 1989

\begin{tabular}{|c|c|c|c|}
\hline & October & November & Cumulative \\
\hline \multicolumn{4}{|c|}{ Expected value $=179.8 \mathrm{mg} / \mathrm{dl}(4.65 \mathrm{mmol} / \mathrm{l})$} \\
\hline $\begin{array}{l}\mathrm{N} \\
\text { Mean } \\
\text { Bias (\%) } \\
\text { CV }(\%)\end{array}$ & $\begin{array}{l}32 \\
180.2(4.66) \\
+0.18 \\
0.58\end{array}$ & $\begin{array}{l}22 \\
180.5(4.67) \\
+0.37 \\
0.59\end{array}$ & $\begin{array}{l}190 \\
180.0(4.65) \\
+0.09 \\
1.53\end{array}$ \\
\hline \multicolumn{4}{|c|}{ Expected value $=276.2 \mathrm{mg} / \mathrm{dl}(7.14 \mathrm{mmol} / \mathrm{l})$} \\
\hline $\begin{array}{l}\mathrm{N} \\
\text { Mean } \\
\text { Bias (\%) } \\
\text { CV (\%). }\end{array}$ & $\begin{array}{l}31 \\
277.0(7.16) \\
+0.30 \\
0.64\end{array}$ & $\begin{array}{l}18 \\
247.7(7.10) \\
-0.53 \\
1.10\end{array}$ & $\begin{array}{l}183 \\
275.2(7.12) \\
-0.38 \\
1.07\end{array}$ \\
\hline \multicolumn{4}{|c|}{ Expected value $=298.6 \mathrm{mg} / \mathrm{dl}(7.72 \mathrm{mmol} / \mathrm{l})$} \\
\hline $\begin{array}{l}\mathrm{N} \\
\text { Mean } \\
\text { Bias (\%) } \\
\text { CV }(\%)\end{array}$ & $\begin{array}{l}12 \\
300.8(7.78) \\
+0.71 \\
0.38\end{array}$ & $\begin{array}{l}8 \\
301.6(7.80) \\
+1.09 \\
0.43\end{array}$ & $\begin{array}{l}239 \\
298.9(7.73) \\
+0.97 \\
0.97\end{array}$ \\
\hline
\end{tabular}

CDC and NIST have collaborated since 1978 to maintain a defined accuracy base with the CDC reference method and the NIST definitive method. Five frozen serum pools were used originally to compare the reference method with the definitive method. The agreement between the two methods was considered excellent with a difference of less than $1.0 \%$ of all five pools (2). In 1989, comparisons of the reference method and definitive method revealed excellent agreement $(0.41 \%)$ on standard solutions (SRM $911 \mathrm{~b}$ ) and good agreement $(1.6 \%)$ on fresh, frozen, or lyophilized sera (13). Unpublished experimental studies at $\mathrm{CDC}$ on potential interferences in the reference method indicate that this difference in level of results between the reference method and definitive method results largely from sterols in serum (14).

Since 1961, the CDC total cholesterol reference method has served as a part of the accuracy base for the CDC-National Heart, Lung, and Blood Institute Lipid Standardization Programme. This accuracy base has been transferred through frozen serum reference materials distributed to the several hundred U.S. participants, as well as to many international laboratories. The reliability of the reference method has made it possible to assure the accuracy of laboratories supporting more than 30 cardiovascular epidemiologic or clinical investigations coordinated by CDC-National Heart, Lung, and Blood Institute, such as the Coronary Drug Project (15), the Lipid Research Clinics (16), Multiple Risk Factor Intervention Trial (17), and the Hypertension Detection and Follow-up Study (18).

The NCCLS's National Reference System for the Clinical Laboratory Council has adopted the CDC reference method as its national reference method for cholesterol (19). The National Reference System for the Clinical Laboratory Council has designated the NIST definitive method, the CDC reference method, the NIST certified pure cholesterol SRM 911, and the CDC-certified serum-based secondary reference materials as the components of the National Reference System for Cholesterol (3).

The National Reference Method Laboratory Network has been formed by $\mathrm{CDC}$ to provide resources for accurate calibration of manufacturers' total cholesterol analytical diagnostic products and accurate confirmatory analysis for clinical laboratories (2). Calibration with fresh specimens has been necessary for some of the new total cholesterol reagent analytical systems that exhibit matrix effects with liquid, frozen, or lyophilized reference materials. The protocol used by the Network utilizes the NCCLS recommendation on procedure for comparison of methods using fresh 
patient specimens (20). Currently, the network includes nine laboratories in the United States and one in the Netherlands: University of Minnesota, Baylor College of Medicine, Wisconsin State Laboratory of Hygiene, Cleveland Clinic Foundation, New York State Department of Health, Northwest Lipid Research Center in Seattle, Pennsylvania State Department of Health, Washington University in St. Louis, USDA Nutrition Research Center on Aging at Tufts University, and Rotterdam Academic Hospital. Network laboratories must document a $\mathrm{CV}$ of less than $2 \%$ and a bias of less than $1.5 \%$ at 3-month intervals in the CDC-National Heart, Lung, and Blood Institute Lipid Standardization Program.

\section{Interim Triacylglycerol Reference Method}

An in-house triacylglycerol reference method was established at CDC in 1963 on the basis of the method of Carlson $(21,22)$ and the techniques of Van Handel \& Zilversmit (23) and Lofland (24). The in-house method involves silicic acid-chloroform extraction for $1 \mathrm{~h}$ at $25^{\circ} \mathrm{C}$, evaporation of an aliquot in a vacuum oven at $50^{\circ} \mathrm{C}$, chemical hydrolysis with $2.5 \mathrm{~g} / 1$ alcoholic $\mathrm{KOH}$ for $30 \mathrm{~min}$ at $70^{\circ} \mathrm{C}$, allowing the solution to stand overnight at $4{ }^{\circ} \mathrm{C}$ after neutralization with $0.1 \mathrm{~mol} / 1 \mathrm{H}_{2} \mathrm{SO}_{4}$, colour development by metaperiodate-arsenite-chromotropic acid reagent at $95^{\circ} \mathrm{C}$, and reading of the cooled solution in flow cell at $570 \mathrm{~nm}$. The specificity of this method is largely due to the chloroform-silicic acid extraction procedure that removes free glycerol and retains minimally monoacylglycerol and diacylglycerol. The primary standard can be either pure triolein, pure palmitin, or a $2: 1 \mathrm{mix}$ ture, respectively. Glycerol or mannitol can be used as a primary standard in calibrating or monitoring the last step in the method that analyzes the free glycerol. Laboratories' findings can lack comparability if different primary standards are used, unless results are expressed in $\mathrm{mmol} / \mathrm{l}$. True bias is not

Tab. 2. Triacylglycerol reference method performance, CDC 1989

\begin{tabular}{lccc}
\hline & October & November & Cumulative \\
\hline $\mathrm{N}$ & 20 & 12 & 364 \\
Expected value & $=0.907 \mathrm{mmol} / 1$ & & \\
Mean & 0.918 & 0.910 & 0.917 \\
Bias (\%) & +1.20 & +0.33 & +1.13 \\
$\mathrm{CV}(\%)$ & 4.0 & 2.2 & 5.6 \\
& & & \\
Expected value & $2.381 \mathrm{mmol} / 1$ & & \\
Mean & 2.39 & 2.35 & 2.36 \\
Bias (\%) & +0.49 & -1.41 & -0.86 \\
CV (\%) & 3.9 & 2.7 & 3.0 \\
\hline
\end{tabular}

known, because a definitive method is not available. The attainable precision usually ranges between $3 \%$ and $5 \% \mathrm{CV}$ (tab. 2).

The major problems with the use of this triacylglycerol method as a reference method at CDC are

1) extraction with carcinogenic ' $\mathrm{CHCl}_{3}$,

2) difficulty arising from the presence of silicic acid "fines" or very small particles in extracts,

3) impurity, instability and a potentially different degree of hydrolysis of different triacylglycerols,

4) unknown commutability of lyophilized reference material, and

5) questionable transferability of this chromotropic acid method.

Investigators are searching for a triacylglycerol reference method that may circumvent these problems'.

This CDC in-house triacylglycerol reference method has been designated as the interim triacylglycerol candidate reference method for the National Reference System and serves as the selected reference method for the CDC-maintained accuracy base for the CDCNational Heart, Lung, and Blood Institute Lipid Standardization Programme and for the dedicated laboratories of National Heart, Lung, and Blood Institute clinical and epidemiologic cardiovaścular investigations and trials.

\section{Interim HDL Cholesterol Reference Method}

A CDC in-house HDL cholesterol reference method combines removal of very low density lipoprotein cholesterol (VLDL) by the Beta Quan ultracentrifugal procedure (25), isolation of HDL cholesterol by precipitation of LDL cholesterol from the $1.006 \mathrm{~kg} / \mathrm{l}$ Beta Quan bottom fraction by $46 \mathrm{mmol} / \mathrm{l}$ manganese and $1.3 \mathrm{~g} / 1$ heparin reagent (25), and cholesterol analysis of the HDL cholesterol supernate by the National Reference System for Cholesterol total cholesterol reference method $(6,7)$. The primary standard is NIST cholesterol SRM 911 (8), and it must cover the low range of serum HDL cholesterol values, which is different from the range of serum total cholesterol. HDL cholesterol measurements are monitored with both pure cholesterol and frozen, fresh serum secondary standards. Precision for the CDC in-house HDL cholesterol reference method on low cholesterol primary standards is between $1 \%$ and $2 \% \mathrm{CV}$, and on frozen serum secondary reference materials, it is between $2.5 \%$ and $4 \%$ (tab. 3). True bias is not known because a definitive method is not available for HDL cholesterol measurements. 
Tab. 3. HDL cholesterol reference method performance, CDC 1989

\begin{tabular}{|c|c|c|c|c|}
\hline \multirow{2}{*}{$\begin{array}{l}\text { Pool } \\
\text { prepared }\end{array}$} & \multicolumn{3}{|c|}{ HDL cholesterol mean concentration } & \multirow{2}{*}{$\begin{array}{l}\text { Total } \\
\text { CV \% }\end{array}$} \\
\hline & $\overline{\mathrm{N}}$ & $\mathrm{mg} / \mathrm{dl}$ & $\mathrm{mmol} / \mathrm{l}$ & \\
\hline $7-84$ & 470 & 47.0 & 1.22 & 3.0 \\
\hline $2-87$ & 149 & 39.0 & 1.01 & 3.3 \\
\hline \multicolumn{5}{|c|}{ Low cholesterol mean concentration } \\
\hline $\begin{array}{l}3-85 \\
8-87\end{array}$ & $\begin{array}{r}488 \\
72\end{array}$ & $\begin{array}{l}51.1 \\
52.5\end{array}$ & $\begin{array}{l}1.32 \\
1.36\end{array}$ & $\begin{array}{l}1.8 \\
1.6\end{array}$ \\
\hline
\end{tabular}

This HDL cholesterol method has served as the reference method for the CDC-National Heart, Lung, and Blood Institute epidemiological and clinical investigations (25).

The HDL cholesterol method is also used as part of the CDC interim reference methods for VLDL and LDL cholesterol. The CDC interim reference method values for VLDL cholesterol are calculated from serum total cholesterol minus Beta Quan bottom fraction cholesterol determined by the National Reference System for Cholesterol cholesterol reference method. The CDC interim LDL reference method values are calculated from Beta Quan bottom fraction cholesterol minus HDL cholesterol determined by National Reference System for Cholesterol total cholesterol method. This interim LDL reference method determines not only the LDL, but also intermediate-density lipoproteins (IDL) and $\mathrm{Lp}$ (a) constituents as measured in Friedewald procedure (26) or in the 1.006$1.063 \mathrm{~kg} / \mathrm{l}$ ultracentrifugal fractions (25).

The major problems with the interim HDL cholesterol reference method are that it has

1) no definitive method,

2) no accepted primary standard, and

3) questionable traceability to clinical and research laboratory methods that possess matrix effects.

\section{CDC In-House Apolipoprotein B Radioimmunoassay} Method

A competitive radioimmunoassay (RIA) method has been selected and is being evaluated as an interim apolipoprotein B reference method for use in the International Apolipoprotein Standardization Programme conducted by CDC. To conduct this immunoassay, a $1: 100$ dilution of sample is incubated with goat anti-LDL antibody at $37^{\circ} \mathrm{C}$ for $1 \mathrm{~h}$ in the presence of cholate and bovine serum albumin; iodinated LDL is added, and the solution is further incubated at $4^{\circ} \mathrm{C}$ for $16 \mathrm{~h}$; donkey anti-anti-LDL second anti- body is added, and the solution is incubated at $4{ }^{\circ} \mathrm{C}$ for $3 \mathrm{~h}$ in the presence of polyethyleneglycol; centrifugation is conducted at $2500 \mathrm{~min}^{-1}$ for $20 \mathrm{~min}$; the supernant is decanted with blotting; and radioactivity of precipitate is counted. The primary standard is an LDL solution ultracentrifugally prepared at 1.030 $1.050 \mathrm{~kg} / \mathrm{l}(27)$. The results are calculated from bound/ free ratio counts per minute versus log concentration within the range of $0.25-2.00 \mathrm{~g} / 1$ of apolipoprotein B. This method has an intrassay variability of about $2 \% \mathrm{CV}$ and an interassay of less than $6 \% \mathrm{CV}$. True bias is not known since a definitive method is not available for apolipoprotein $B$ measurements.

Major problems exist inherently in any potential immunological reference method for apolipoprotein B measurements. Immunoassays require sensitivity and specificity of antisera, highly accurate dilutions, linear and parallel dose-response curves, and reproducible preparations of primary standards. Reported amonglaboratory variation within the methods can have an average $\mathrm{CV}$ of between $20 \%$ and $25 \%$ for apolipoprotein B (28). The proposed (at $1.030-1.050 \mathrm{~kg} / \mathrm{l}$ ultracentrifugally prepared) LDL primary standard provides an LDL preparation with decreased IDL and $\mathrm{Lp}$ (a) but shows limited immunological stability and uncertainty in protein analysis (29). Tracing an apolipoprotein B reference method to clinical and research apolipoprotein $B$ immunochemical methods is difficult because of large matrix effects of reference materials in certain methods $(28,30)$.

During 1990, the IFCC Committee on Apolipoproteins and manufacturers of apolipoprotein diagnostic products are evaluating potential stabilized liquid serum reference materials for use as apolipoprotein B secondary serum standards. These materials, along with frozen serum pools stored at $-70^{\circ} \mathrm{C}$, will be used in standardization programmes of manufacturers' apolipoprotein B diagnostic products. Difficulties and current recommendations on the standardization of apolipoprotein B measurements have been thoroughly discussed in recent publications $(31-33)$.

\section{CDC In-House Apolipoprotein A-1 Reference Method}

A competitive RIA method, developed for use as a $\mathrm{CDC}$ in-house reference method for apolipoprotein A-1, is similar to the method developed for apolipoprotein B. The apolipoprotein A-1 RIA method utilizes goat polyclonal anti-apolipoprotein A-1 antiserum, and solid phase lactoperoxidase for the iodination of purified apolipoprotein A-1. The apolipoprotein A-1 primary standard is a freshly prepared, liquid, delipidated, purified preparation, confirmed for purity by amino acid analysis. The standard dis- 
placement curve ranges between 0.50 and $2.0 \mathrm{~g} / 1$ where serum samples are diluted $1: 100$ in one step. Precision measurements give an intra-assay $\mathrm{CV}$ of about $2 \%$, and an inter-assay CV of less than $6 \%$. Tracing clinical methods to a reference method for apolipoprotein A-1 should not be difficult since among-method source of variation is negligible for apolipoprotein A1 measurements (28).

A lyophilized, purified, and delipidated proposed apolipoprotein A-1 primary standard is currently being evaluated by the European Cummunity Bureau of Reference in Brussels and the IFCC Committee on Apolipoproteins. Manufacturers of apolipoprotein diagnostic products and this IFCC committee are collaborating to develop a commutable lyophilized apolipoprotein A-1 serum secondary standard. This project seeks to gain comparability of results among com-

\section{References}

1. Brown, S. S., Büttner, J., Mitchell, F. L., Rubin, M. \& Cooper, G. R. (1976) Response to Neil, D. W. \& Doggart, J. R. When is a Reference Method a Reference Method? Clin. Chem. 22, 285-286.

2. Myers, G. L., Cooper, G. R., Winn, C. L. \& Smith, S. J. (1989) The Centers for Disease Control-National Heart, Lung, and Blood Institute Lipid Standardization Program: An Approach to Accurate and Precise Lipid Measurements. In: Cholesterol Screening (Rifkind, B. M. \& Lippel, K., eds.) pp. 105-136, W. B. Saunders Co., Philadelphia.

3. Vanderlinde, R. E., Bowers, G. N., Schaffer, R. \& Edwards, G. C. (1989) The National Reference System for Cholesterol. In: Cholesterol Screening (Rifkind, B. M. \& Lippel, K., eds.) pp. 89-104, W. B. Saunders Co., Philadelphia.

4. Cohen, A., Hertz, H. S., Mandel, J., Paule, R. C., Schaffer, R., Sniegoski, L. T., Sun, T., Welch, M. J. \& White, E. V. (1980) Total Serum Cholesterol by Isotope Dilution-Mass Spectrometry: A Candidate Definitive Method. Clin. Chem. 26, 854-860.

5. Abell, L. L., Levy, B. B., Brodie, B. B. \& Kendall, F. E. (1952) A Simplified Method for the Estimation of Total Cholesterol in Serum and Demonstration of its Specificity. J. Biol. Chem. 195, 357-366.

6. Duncan, I. W., Mather, A. \& Cooper, G. R. (1982) The Procedure for the Proposed Cholesterol Reference Method. Lipid Standardization Activity, Center for Environmental Health, Centers for Disease Control, MS F20, Atlanta, Georgia 30333.

7. Cooper, G. R., Smith, S. J., Duncan, I. W., Mather, A., and 14 collaborating groups (1986) Interlaboratory Testing of the Transferability of a Candidate Reference Method for Total Cholesterol in Serum. Clin. Chem. 32, 921-929.

8. National Institute of Standards and Technology, Office of Standard Reference Materials, Gaithersburg, Maryland, 20899.

9. National Committee for Clinical Laboratory Standards (1984) Tentative Guideline NRSCC-T. Development of Reference Methods in Clinical Chemistry for the National Reference System. NCCLS, Villanova, Pennsylvania 19085.

10. Stender, S. (1989) Reference methods - with Special Reference to Cholesterol. Scand. J. Clin. Lab. Invest. 49 (Suppl. 194), 63-67.

11. Stamm, D. (1979) Reference Materials and Reference Methods in Clinical Chemistry. J. Clin. Chem. Clin. Biochem. 17, 283-287. mercial apolipoprotein A-1 diagnostic products. The $\mathrm{CDC}$ is supporting this effort by analysing these reference materials with the RIA method and studying potential primary standards and their problems.

\section{Conclusions}

\section{$: 1$}

A reference method has been developed for total cholesterol for national and international reference systems. Interim reference methods are being used for triacylglycerol, HDL cholesterol and LDL cholesterol measurements. Potential candidate reference methods are being developed and evaluated for apolipoprotein A-1 and B measurements by different apolipoprotein investigators. Continuing worldwide efforts to improve the methodology should lead to an accepted international accuracy base for the clinically useful lipid, lipoprotein, and apolipoprotein measurements.

12. Boutwell, J. H. (1978) Proceedings of the Conference on a National Understanding for the Development of Reference Materials and Methods for Clinical Chemistry meeting. American Association for Clinical Chemistry, Washington, D.C. 20006.

13. Ellerbe, P., Myers, G. L., Cooper, G. R., Hertz, H. S., Sniegoski, L. T., Welch, M. J. \& White, E. V. (1990) A Comparison of Results for Cholesterol in Human Serum Obtained by the Reference Method and by the Definitive Method of the National Reference System for Cholesterol. Clin. Chem. 36, 370-375.

14. Bernert, J. T. Jr. (1990) Evaluation of the Accuracy of the NRS Total Cholesterol Reference Method. Clin. Chem. (In press)

15. Coronary Drug Project Research Group (1975) Clofibrate and Niacin in Coronary Heart Disease. J. Am. Med. Ass. $231,360-381$.

16. Lipid Research Clinics Program (1984) The Lipid Research Clinics Coronary Primary Prevention Trial Results. Reduction in Incidence of Coronary Heart Disease. J. Am. Med. Ass. 251, 351-364.

17. Multiple Risk Factor Intervention Trial Research Group (1982) Multiple Risk Factor Intervention Trial: Risk Factor Changes and Mortality Results. J. Am. Med. Ass. 248, $1465-1477$.

18. Hypertension Detection and Follow-up Program Cooperative Group (1979) Five-year Findings of the Hypertension Detection of Follow-up Program. I. Reduction in Mortality of Persons with High Blood Pressure, including Mild Hypertension. J. Am. Med. Ass. 242, 2562-2577.

19. National Committee for Clinical Laboratory Standards (1987) NCCLS Document RS3-A. Cholesterol: Approved Summary of Methods and Materials Credentialed by the NRSCL Council. NCCLS, Villanova, Pennsylvania 19085.

20. National Committee for Clinical Laboratory Standards (1986) NCCLS Document EP9-P. User Comparison of Quantitative Clinical Laboratory Methods using Patient Samples. NCCLS, Villanova, Pennsylvania 19085.

21. Carlson, L. A. \& Wadstrom, L. B. (1959) Determination of Glycerides in Blood Serum. Clin. Chim. Acta 4, 197205.

22. Carlson, L. A. (1963) Determination of Serum Triglycerides. J. Atherosclerosis Res. 3, 334-336.

23. Van Handel, E. \& Zilversmit, D..B. (1957) Micromethod for the Direct Determination of Ttiglycerides. J. Lab. Clin. Med. 50, 152-157. 
24. Lofland, H. B. Jr. (1964) A Semiautomated Procedure for the Determination of Triglycerides in Serum. Anal. Biochem. 9, 393-400.

25. Lipid Research Clinics Program (1982) Hainline, A. Jr., Karon, J. \& Lippel, K. (eds.) Manual of Laboratory Operations, Lipid and Lipoprotein Analysis, 2nd ed., HEW Publ. No. (NIH) 75-628 (revised). National Heart, Lung, and Blood Institute Bethesda, Maryland (U. S. Government Printing Office No. 1982-361-132:678).

26. Friedewald, W. T., Levy, R. 1. \& Fredrickson, D. S. (1972) Estimation of the Concentration of Low-Density Lipoprotein Cholesterol in Plasma, Without the Use of the Preparative Ultracentrifuge. Clin. Chem. 18, 499-502.

27. Albers, J. J., Lodge, M. S. \& Curtiss, L. K. (1989) Evaluation of a Monoclonal Antibody-based Linked Immunosorbent Assay as a Candidate Reference Method for the Measurement of Apolipoprotein B-100. J. Lipid Res. 30, 1445-1458.

28. Smith, S. J., Henderson, L. O., Hannon, W. H. \& Cooper, G. R. (1990) Effects of Analytical Method and Lyophilized Serum on Measurements of Apolipoproteins A-1 and B: An International Study. Clin. Chem. 36, 290-296.
29. Henderson, L. O., Powell, M. K., Smith, S. J., Hannon, W. H., Cooper, G. R. \& Marcovina, S. M. (1990) Impact of Protein Measurements on Standardization of Apolipoproteins A-1 and B Assays. Clin. Chem. 36, 1911-1917.

30. Marcovina, S. M., Adolphson, J. L., Parlavecchia, M. \& Albers, J. J. (1990) Effects of Lyophilization of Serum on the Measurements of Apolipoprotein A-1 and B. Clin. Chem. 36, 366-369.

31. Albers, J. J. \& Marcovina, S. M. (1989) Standardization of Apolipoprotein B and A-1 Measurements. Clin. Chem. $35,1357-1361$

32. Marcovina, S. M. \& Albers, J. J. (1989) Guidelines for the Standardization of the Immunochemical Determination of Apolipoprotein A-1 and B. IFCC Meeting for Standardization of Apolipoprotein A-1 and B Measurements, (basis for future consensus), Vienna, Austria, April 18-19, 1989. Clin. Chem. 35, 2009-2015.

33. Cooper, G. R., Smith, S. J., Henderson, L. O., Hannon, W. H. (1988) Standardization of Apolipoprotein Measurements. In: Recent aspects of diagnosis and treatment of lipoprotein disorders: impact of prevention of atherosclerotic diseases (Widhalm, K. \& Naito, H. K., eds.) pp. 155-174, Alan R. Liss, New York.

Dr. Gerald R. Cooper

Centers for Disease Control

Mailstop: F20

Atlanta

Georgia 30333

U.S. A. 


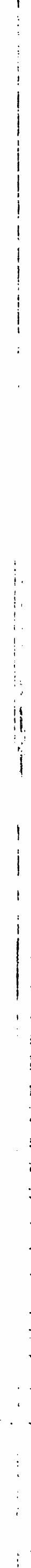

